\title{
Village Chicken Breeding Objectives and Trait Preferences of Chicken Producers' in Western Amhara, Ethiopia
}

\author{
Birhan kassa $^{1 *} \quad$ Yosef Tadesse $^{2} \quad$ Wondmeneh Esatu $^{3} \quad$ Tadelle Dessie $^{3}$ \\ 1.Andassa Livestock Research Center of Amhara Regional Agricultural Research Institute, P.o.box:27, Bahir \\ Dar, Ethiopia \\ 2.Haramaya University College of Agriculture and Environmental Science, P.o.box:138, Haramaya, Ethiopia \\ 3.International Livestock Research Institute, P.o.box:5689, Addis Ababa, Ethiopia
}

\begin{abstract}
This study was carried out to generate base line information on village chicken production objective, breeding practice and trait preference of chicken producers in South Achefre, Banija and FagitaLekoma districts of western Amhara. Multi stage sampling procedures were employed to select the study villages and respondents, where nine villages and 180 respondents were selected by purposive and random sampling techniques, respectively. Data were collected by individual survey using Open Data Kit. The collected data were analyzed using descriptive statistics of SPSS version 20 and ranking index. Main purposes of keeping chicken in the study area are sale of egg and live adult chicken and farmers have a multiple breeding practice. Exotic breed was the first priority of chicken producers. The three most preferred trait for the selection of breeding hen are egg production trait, disease resistance and mothering ability, while the three most preferred trait for the selection of breeding cockare body conformation/ physical appearance, body size and diseases resistance. Comprehensible knowledge on breeding practices, objectives and trait preferences of chicken owners are crucial for development of holistic and applicable genetic improvement program. Hence, production objectives and trait preference should incorporate in designing genetic improvement breeding programs to assure sustainable utilization and improvement of indigenous chickens. Keywords: Breeding hen, Breeding practices, Breeding objectives, Trait preference
\end{abstract}

DOI: $10.7176 / \mathrm{JBAH} / 10-9-03$

Publication date:May $31^{\text {st }} 2020$

\section{INTRODUCTION}

The total chicken population in Ethiopia is estimated at 60.51 million (CSA, 2016), with regard to breed, 94.33 percent of the total poultry were indigenous chickens, while the remaining 3.21 and 2.47 percent of the total poultry were reported to be hybrid and exotic, respectively. Indigenous chickens have been distributed in different agroecological zones of Ethiopia and thiswide distributionindicatestheiradaptivepotential todifferent environmental conditions, diseases and other stresses (Halima, 2007).On the contrary to this huge size and adaptive behavior of indiegineus chickens, their production potenitial is low. Efforts to improve the performance of local chickens through cross breeding with exotic breeds were not successful (Dana et al., 2010) which are attributed to the dissemination of inappropriate technologies without understanding of production environments under which indigenous chickens are raised and the lack of information on breeding objectives and farmers' trait preferences. In Ethiopia like other developing countries, agro-ecologically based breeding programs for indigenous chicken breeds are lacking (Dana et al., 2010). Thierfore, Base line information on indigenous breeding practices, production objectives and farmers' trait preferences require for designing, planning and implementing sustainable and holistic genetic improvement programmes of indigenous chickens so as to ensure sustainable improvement, utilization and conservation of indigenous chicken genetic resources and to uplift their contributions to improve the livelihoods of smallholder farmers. Thierfore, this study was aimed to assess breeding objective, breeding practice and triat preference of chicken producers in the study area.

\section{MATERIALS AND METHODS}

\subsection{Area Description}

This study was conducted in three districts of western Amhara, Ethiopia (figure 1) namely South Achefere, Banija and FigitaLekoma districts. These districts were selected based on number of chickens, number of (smallholder) households rearing chicken, percent contribution of chicken to household income/nutrition, percent market share captured by smallholders, availability of feed resources for chicken and diversity across the region and strategically selected for their accessibility and safe for research work. South Achefer district is found in West Gojam administrative zone of Amhara National Regional State (ANRS). It lies $11^{\circ} 04^{\prime}-11^{\circ} 05^{\prime} \mathrm{N}$ latitude and $36^{\circ} 52^{\prime}-$ $36^{\circ} 54^{\prime}$ E longitude with altitude of $1500-2600$ meters above sea level. The total annual rainfall is range from $1365-1623 \mathrm{~mm}$ and the temperature is ranged from 11.8 to $28.4^{\circ} \mathrm{C}$ (CSA, 2008). Banija district is found in Awi Zone administrative zone of Amhara National Regional State (ANRS). The district lies within $11.36^{\circ}$ to $12^{0} 09^{\prime} \mathrm{N}$ latitude and $36^{0} 95^{\prime}-38^{0} 95^{\prime} \mathrm{E}$ and the altitude of the study area ranges from 1800 to $2953 \mathrm{~m}$.a.s.l. The mean annual rainfall of the study area ranges from $1700 \mathrm{~mm}$ to $2560 \mathrm{~mm}$, with mean monthly minimum and maximum 
temperature ranging from $7^{\circ} \mathrm{C}$ to $12^{\circ} \mathrm{C}$, and $20^{\circ} \mathrm{C}$ to $25^{\circ} \mathrm{C}$, respectively $(\mathrm{CSA}, 2008)$. FagitaLekomais found in Awi Zone administrative zone of Amhara National Regional State (ANRS). The district is located at $10^{0} 52^{\prime}$ to $11^{\circ} 03^{\prime} \mathrm{N}$ latitude and $36^{\circ} 38^{\prime}$ to $37^{0} 8^{\prime} \mathrm{E}$ longitudes and altitude ranges from 2000-3200 m above sea level. Average annual rainfall of the district is $2379 \mathrm{~mm}$. Temperature varies between the mean annual maximum of $25^{\circ} \mathrm{C}$ and mean annual minimum of $11^{\circ} \mathrm{C}$ across the elevation gradient (CSA, 2008).

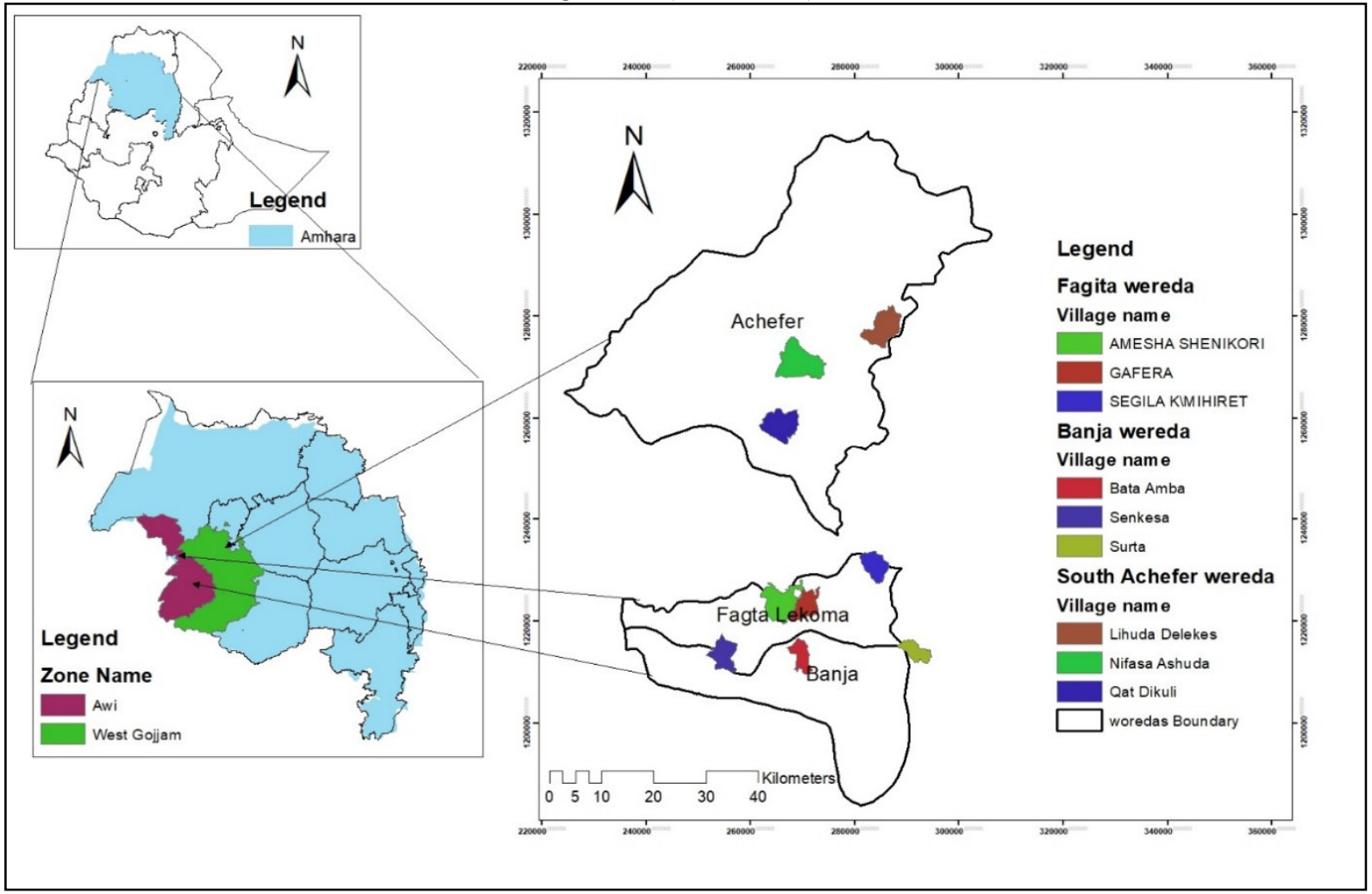

Figure 1. Location map of study area

\subsection{Sampling Technique and Sample Size}

Multi-stage sampling technique (purposive and random) were applied for the selection of both villages and chicken producer households in each district. Villages were selected based on number of chickens, number of (smallholder) households rearing chicken, availability of feed resources for chicken and for their accessibility and safe for research work. Based on those criteria three villages per district and a total of nine villages in the three districts were selected. Computerized random sampling procedures were applied to select 20 village chicken producer's households in each village and a total of 180 households were selected.

\subsection{Data Collection}

Data on household characteristics, production objectives, breeding practicesand farmers' trait preferences of chicken under village production system were collected through individual interview using a structured questionnaire survey tool by Open Data Kit (ODK) data collection tool and then enriched with one focus group discussion in each district with 8 memerships in each group composed of key informants like; expert in rural development of the respective district, elders, women and youths.

\subsection{StasicalAnalysis}

Descriptive statistics procedures of SPSS version 20 were employed when apropirate. The rank of breeding objectives, breed prefence and trait preferences and prioritized traits to be improved through genetic improvement interventions from individual respondents obtained through direct interview in the survey was analyzed using ranking index: Index $=\Sigma(\mathrm{n}$ x number of HHs ranked $1 \mathrm{st})+(\mathrm{n}-1) \mathrm{x}$ number of HHs ranked $2 \mathrm{nd})+\ldots+1 \mathrm{x}$ number of HHs ranked last) for a particular trait divided by the $\Sigma$ (n x number of HHs ranked 1st + (n-1) x number of HHs ranked 2 nd $+\ldots+1 \mathrm{x}$ number of $\mathrm{HHs}$ ranked last) for all traits, and where $\mathrm{n}=$ number of traits under consideration. The variable with the highest index value is the highest economically important trait (Kosgey, 2004). 


\section{RESULTS AND DISCUSSIONS}

\subsection{Household Charactersics}

From the total respondents, majority of them were male (Table 1) and the mean ages of respondents in the study area were between the age of 46.18-47.5 years. The mean family size of the study area was $5.75 \pm 1.91$. The higher and the lower family sizes were exhibited in Achfer and Banija districts, respectively. Difference in family size might be related to the wealth of the household which is cattle population and landholding of south Achefere district is higher than Banija districts intern have had higher family size. The average family size in the study area was higher than the national average of 4.6 persons (CSA, (2011) and the average family size (5.08) of Dabat and Dabark districts of north Gondar zone, Amhara region (Netsanet, 2017).But comparable to family size of 5.4 per household for Northwestern Amhara region was observed (Halima, 2007).

The overall mean of land holding per household in the study area was $1.18 \pm 0.61$ ha. This result was similar with the reported $1.23 \pm 1.23$ hectare/household of Burie district of western Amhara region (Fisheaet al., 2010) but higher than 1.0 ha reported from lowland and midland of central Tigray (Alemet al., 2013). The mean land holding per household in south Achefere and FagitaLekoma districts were higher than Banija district. Higher land area coverage and lower population density of the district contributed for higher land holding per household in South Achefere district than Banija district.

The experience (years) of chicken keeping was significantly $(\mathrm{P}<0.05)$ higher in South Achefere district than other districts(Table 1). Chicken keeping experience is related to knowledge of husbandry and management practices, therefore the more the experience of keeping chicken the better knowledge would develop about the husbandry and management practices of chicken and are better able to assess the characteristics of modern technology than less experienced, and hence a higher probability of adopting the new chicken breeds and management practice.

Table 1. Household characteristics by district in in the study area

\begin{tabular}{|c|c|c|c|c|}
\hline Variables & $\begin{array}{l}\text { South Achefer } \\
(\mathrm{N}=60)\end{array}$ & Banija $(\mathrm{N}=60)$ & $\begin{array}{l}\text { FagitaLekoma } \\
(\mathrm{N}=60)\end{array}$ & Overall mean \\
\hline \multicolumn{5}{|l|}{ Sex of Respondents (\%) } \\
\hline Male & 91.67 & 81.67 & 88.33 & 87.2 \\
\hline Female & 8.33 & 18.33 & 11.67 & 12.8 \\
\hline Average Age (years) & 46.18 & 46.27 & 47.5 & 46.65 \\
\hline Average year of schooling & $2.53 \pm 3.84$ & $2.68 \pm 4.09$ & $2.43 \pm 3.13$ & $2.55 \pm 3.69$ \\
\hline Average family size $($ mean \pm SD) & $6.17^{\mathrm{a}} \pm 1.82$ & $5.35^{\mathrm{b}} \pm 2.09$ & $5.75^{\mathrm{ab}} \pm 1.75$ & $5.75 \pm 1.91$ \\
\hline Land holding(ha) (mean \pm SD) & $1.3^{\mathrm{a}} \pm 0.6$ & $0.9^{\mathrm{b}} \pm 0.4$ & $1.3^{\mathrm{a}} \pm 0.61$ & $1.18 \pm 0.61$ \\
\hline Chicken keeping experience & $19.65^{\mathrm{a}} \pm 1.43$ & $14.62^{b} \pm 1.53$ & $15.49^{\mathrm{b}} \pm 0.65$ & $16.59 \pm 0.85$ \\
\hline
\end{tabular}

$\overline{a, b}$ Means within a row followed by different superscripts show the presence of significant differences $(P<0.05)$

\subsection{Chicken breeding management}

\subsubsection{Source of Foundation Stock}

Sources of chicken foundation stock of households in the study area are presented in Table 2.According to the respondents the major sources for foundation stock were purchase for local exotic and cross breeds in the study area. But one-fifth of the chicken producers in Banija district donated from different NGOs. The result is in line with Tadelle et al. (2003) and Saloet al. (2016)in which purchase was the main source of foundation stock. Table 2. Source of foundation stock (\%)

\begin{tabular}{|c|c|c|c|c|c|c|c|c|c|c|c|c|c|}
\hline \multirow[t]{2}{*}{ Source } & \multicolumn{3}{|c|}{ South Achefere } & \multicolumn{3}{|c|}{ Banija } & \multicolumn{3}{|c|}{ FagitaLekoma } & \multicolumn{4}{|c|}{ Overall } \\
\hline & $\mathrm{L}$ & $E$ & $\mathrm{C}$ & $\mathrm{L}$ & $\mathrm{E}$ & $\mathrm{C}$ & $\mathrm{L}$ & $\mathrm{E}$ & $\mathrm{C}$ & $\mathrm{L}$ & $\mathrm{E}$ & $\mathrm{C}$ & $\mathrm{TC}$ \\
\hline Purchase & 97.7 & 100 & 100 & 98.3 & 80 & 93.8 & 98.3 & 100 & 96.2 & 97.8 & 95.2 & 96 & 97.2 \\
\hline Gift & 3.3 & - & - & 1.7 & 20 & 6.3 & 1.7 & - & - & 2.2 & 4.8 & 2 & 2.4 \\
\hline Hatched & - & - & - & - & - & - & - & - & 3.8 & - & - & 2 & 0.4 \\
\hline
\end{tabular}

$L=$ local chicken; $E=$ exotic chicken; $C=$ cross chicken (local $X$ exotic); $T C=$ Total chicken

\subsubsection{Breeding practice}

Majotity of (70.5\%) households were practiced uncontrolled mating due to free ranging system whereas, $29.5 \%$ of chicken owners tried to improve their local chicken by control mating through culling poor performance of chickens $(62.5 \%)$, selecting best cocks and layers for breeding purpose from their own flock $(25 \%)$ and cull at early age (12.5\%). This study result revealed better breed improvement than the study reported by Addisu et al. (2013) in north Wollo zone of Amhara Regional State which revealed that $89.2 \%$ of village chicken owners had uncontrolled natural mating system while $10.79 \%$ of them had practiced mate control of their flocks through either retaining best indigenous or exotic cocks with layers $(52.79 \%)$, preventing mate $(24.37 \%)$, cull at early age $(19.19 \%)$ or culling poor productive $(3.55 \%)$. Majority of the respondentswerepracticedbreeding for improving their own indegineous chicken either by cross breeding (20.75), line breeding (25.78) and or cross and line breeding $(53.45)$. 
Table 3.Mating syatem, ways of control for improvement and improving indegineous chicken

\begin{tabular}{|c|c|c|c|c|}
\hline \multirow[t]{2}{*}{ Variables } & \multicolumn{4}{|c|}{ Districts } \\
\hline & South Achefere $(\%)$ & Banija (\%) & FagitaLekoma (\%) & Overall (\%) \\
\hline \multicolumn{5}{|l|}{ Matting system } \\
\hline Controlled mating & $20(33.3)$ & $17(29.3)$ & $16(26.6)$ & $(53) 29.5$ \\
\hline Uncontrolled mating & $40(66.7)$ & $43(71.7)$ & $44(73.3)$ & $(127) 70.5$ \\
\hline \multicolumn{5}{|c|}{ Ways of control for improvement } \\
\hline Culling poor productive & $7(35)$ & $5(29.41)$ & $6(37.5)$ & (18)33.96 \\
\hline Cull at early age & $3(15)$ & $3((17.64)$ & $3(18.75)$ & (9)16.98 \\
\hline Retaining of best ones & $10(50)$ & $9(52.94)$ & $7(43.75)$ & $(27) 50.94$ \\
\hline \multicolumn{5}{|l|}{ Breeding practice } \\
\hline Yes & $55(91.7)$ & $53(88.3)$ & $51(85)$ & $159(88.3)$ \\
\hline No & $5(8.3)$ & $7(11.7)$ & $9(15)$ & $21(11.7)$ \\
\hline \multicolumn{5}{|c|}{ Ways of improving indigenous chicken } \\
\hline Cross breeding & $13(23.6)$ & $12(22.64)$ & $9(17.64)$ & $33(20.75)$ \\
\hline Line breeding & $15(27.72)$ & $13(24.52)$ & $14(27.45)$ & $41(25.78)$ \\
\hline Both & $27(49.09)$ & $27(50.94)$ & $28(54.91)$ & $85(53.45)$ \\
\hline
\end{tabular}

Culling practice of chicken by the respondents in the study area is indicated in Table 4. Majority of the respondents practiced culling in the study area. From the total interviewed chicken producers in the study area majority of them were practiced culling due to poor egg productivity followed by old age. The overall mean age of chickens that culled was $38.53 \pm 9.27$ months.

Table 4. Culling practices andreason for cullingof chicken by respondents in the study area

\begin{tabular}{|c|c|c|c|c|c|}
\hline Parameters & Response & $\begin{array}{l}\text { South Achefer } \\
\quad(\mathrm{N}=60)\end{array}$ & $\begin{array}{c}\text { Banija } \\
(\mathrm{N}=60)\end{array}$ & $\begin{array}{l}\text { FagitaLekoma } \\
(\mathrm{N}=60)\end{array}$ & Overall \\
\hline \multicolumn{6}{|l|}{ Culling practice } \\
\hline & Yes & 85 & 71.7 & 81.7 & 79.3 \\
\hline & No & 15 & 29.3 & 19.3 & 21.7 \\
\hline \multicolumn{6}{|l|}{ Reason for culling } \\
\hline $\begin{array}{l}\text { Due to poor egg } \\
\text { productivity of hen }\end{array}$ & Yes & 60.8 & 81.4 & 80.9 & 73.8 \\
\hline Due to low body weight & Yes & 31.4 & 20.9 & 35.4 & 29.6 \\
\hline Due to poor vitality & Yes & 19.6 & 14 & 22.9 & 19 \\
\hline Due to poor egg quality & Yes & 21.6 & 16.3 & 25 & 21.1 \\
\hline Due to bad plumage color & Yes & 25.6 & 20.9 & 22.9 & 23.2 \\
\hline Due to bird broodiness & Yes & 0 & 4.7 & 0 & 1.4 \\
\hline Due to disease concern & Yes & 18 & 23.8 & 22.9 & 21.4 \\
\hline Due to old age & Yes & 60.9 & 74.4 & 60.4 & 64.8 \\
\hline Mean age of culled chicken & Month & $41.09+9.9$ & $36.88+9.5$ & $37.45 \pm 7.8$ & $38.53+9.3$ \\
\hline
\end{tabular}

\subsubsection{Breeding objective of chicken producers}

The primary purpose of keeping chicken in South Achefer district was for sale of adult chicken followed by for egg sale and for consumption during holidays, whereas for the other two districts the primary purpose of keeping chicken were for egg sale and followed by for adult chicken sale(Table 5). Generally, chickens were used as source of income for rural households in terms of egg sale and live adult chicken sale and the result implicates that farmers have multiple breeding purpose of indigenous chicken. Therefore, to realize the keeping of chicken in rural households of the study area, dual purpose chickens would be suitable to maximize both egg production and growth. Similarly,Fisheaet al. (2010) reported that sale of live chicken for cash income was the first important function of rearing chicken followed by household consumption, use of chicken for cultural/religious ceremonies, job opportunity and egg production in Fogera district of Amhara region. It is also similar with the finding of Hailemichael (2013) who reported that the first most important function of rearing chicken was sale for cash followed by hatching for breeding stock and home consumption. 
Table 5. Ranking of chicken production purpose in the study area

\begin{tabular}{|c|c|c|c|c|c|c|c|}
\hline \multirow[t]{2}{*}{ District } & \multicolumn{7}{|c|}{ Purpose of keeping chicken } \\
\hline & $\begin{array}{l}\text { Meat } \\
\text { consumption }\end{array}$ & $\begin{array}{l}\text { Egg } \\
\text { consumption }\end{array}$ & $\begin{array}{l}\text { Meat } \\
\text { sale }\end{array}$ & Egg sale & $\begin{array}{l}\text { Chick } \\
\text { sale }\end{array}$ & Festivals & $\begin{array}{l}\text { Adult chicken } \\
\text { sales }\end{array}$ \\
\hline \multicolumn{8}{|c|}{ South Achefre $(n=60)$} \\
\hline $\mathrm{R} 1$ & 1 & - & - & 9 & 14 & 4 & 32 \\
\hline $\mathrm{R} 2$ & 2 & 3 & - & 28 & - & 28 & 9 \\
\hline R3 & 7 & 6 & - & 5 & - & 26 & 4 \\
\hline Index & 0.04 & 0.03 & - & 0.25 & 0.12 & 0.21 & 0.34 \\
\hline \multicolumn{8}{|c|}{ Banija $(n=60)$} \\
\hline R1 & - & 5 & - & 31 & 9 & 3 & 14 \\
\hline $\mathrm{R} 2$ & 1 & 7 & 2 & 21 & 10 & - & 18 \\
\hline R3 & 3 & 8 & - & 3 & 3 & 21 & 7 \\
\hline Index & 0.01 & 0.11 & 0.01 & 0.4 & 0.15 & 0.07 & 0.25 \\
\hline \multicolumn{8}{|c|}{$\operatorname{Fagitalekomav}(n=60)$} \\
\hline $\mathrm{R} 1$ & 1 & 7 & - & 38 & - & - & 14 \\
\hline $\mathrm{R} 2$ & 4 & 4 & - & 17 & 6 & 1 & 26 \\
\hline R3 & 7 & 3 & - & 1 & - & 21 & 6 \\
\hline Index & 0.05 & 0.1 & - & 0.45 & 0.04 & 0.07 & 0.3 \\
\hline \multicolumn{8}{|c|}{ Overall $(n=180)$} \\
\hline R1 & 2 & 12 & - & 78 & 23 & 5 & 60 \\
\hline $\mathrm{R} 2$ & 7 & 14 & 2 & 66 & 16 & 19 & 53 \\
\hline R3 & 17 & 17 & - & 9 & 3 & 68 & 17 \\
\hline Index & 0.05 & 0.09 & 0.01 & 0.31 & 0.09 & 0.19 & 0.27 \\
\hline
\end{tabular}

* R1, R2 and R3=Rank 1, 2 and 3 respectively.

\subsubsection{Trait Preference and Selection Criteria of Chicken}

The traits traditionally considered as criteria for selecting breeding stock are important in describing the adaptive attributes and genetic merits of the indigenous chickens and in identifying farmers' choice of chicken breeds and the underlying factors that determine the choice of genetic stock used (Nigussie et al., 2010). Egg production/hen, body weight, plumage color, body conformation / qumena / and diseases resistance were traits preferred by farmer to be improved. For the selection of breeding males and breeding females, chicken producers prefer similar trait categories with different emphasis such as body size, growth rate, feed requirement, body/feather color, leg length, comp shape, wing span, chick production rate, clutch length egg size/weight, cold tolerance, heat/drought tolerance, temperament, scavenging ability, brooding/hatching ability, egg productivity and rearing/mothering ability. Though controlling of chicken mating is difficult in scavenging production system, farmers practice selection for their breeding females and breeding males for the traits they prefer and wants to improve for their production objective.

\subsubsection{Trait preference for breeding hen of chicken producers}

Trait preferences by chicken producers for breeding female are indicated in Table 6. Ranking index from both the survey and focus group discussion result for the trait preference of female chicken indicated that egg production trait was ranked first and followed by disease resistance and mothering ability in all the study districts. This implies that production of high number of eggs was the first preferred trait in all study districts because of the obvious benefits of egg for home consumption, selling for cash and stock replacement.This result is in agreement with Dana et al. (2010) who indicated that egg production as the most important selection criterion in different parts of Ethiopia. This result was also comparable with the reports of Addisu et al. (2013) in which egg production /hen, meat yield and disease resistance were the farmers' preferred traits to be improved through breeding in north Wollo Zone. This shows that there was variation in egg production and resistance for various diseases within and among chicken ecotypes/breeds of the study area. Similarly, majority of the farmers in Kenya considered egg yield as the most important trait followed by mothering ability and body size (Okenoet al., 2011). As a result, all chicken producers gave greatest attention to economic trait (egg production), functional trait (mothering ability) and adaptation trait (disease resistance) rather than reproduction trait and comb type and shape. In general, high index value of egg number, mothering ability and disease resistance is an indicator that chicken producers are not only interested in chicken that can produce more eggs for consumption, hatching and sales but can also brood chicks to weaning because they are the main source of the replacement stock by adapting/fitting the existing environment. 
Table 6. Ranking of trait preferences by the respondents for breeding females in the study area Qualities of a good breeding hen

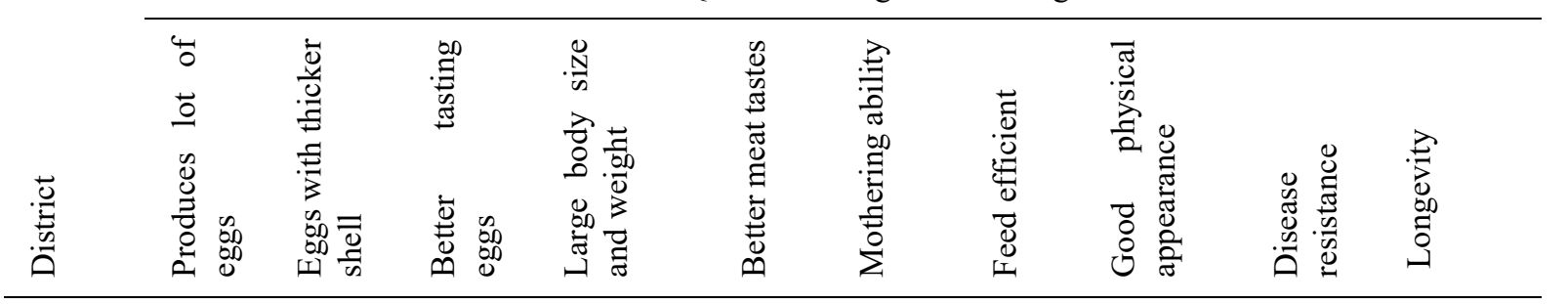

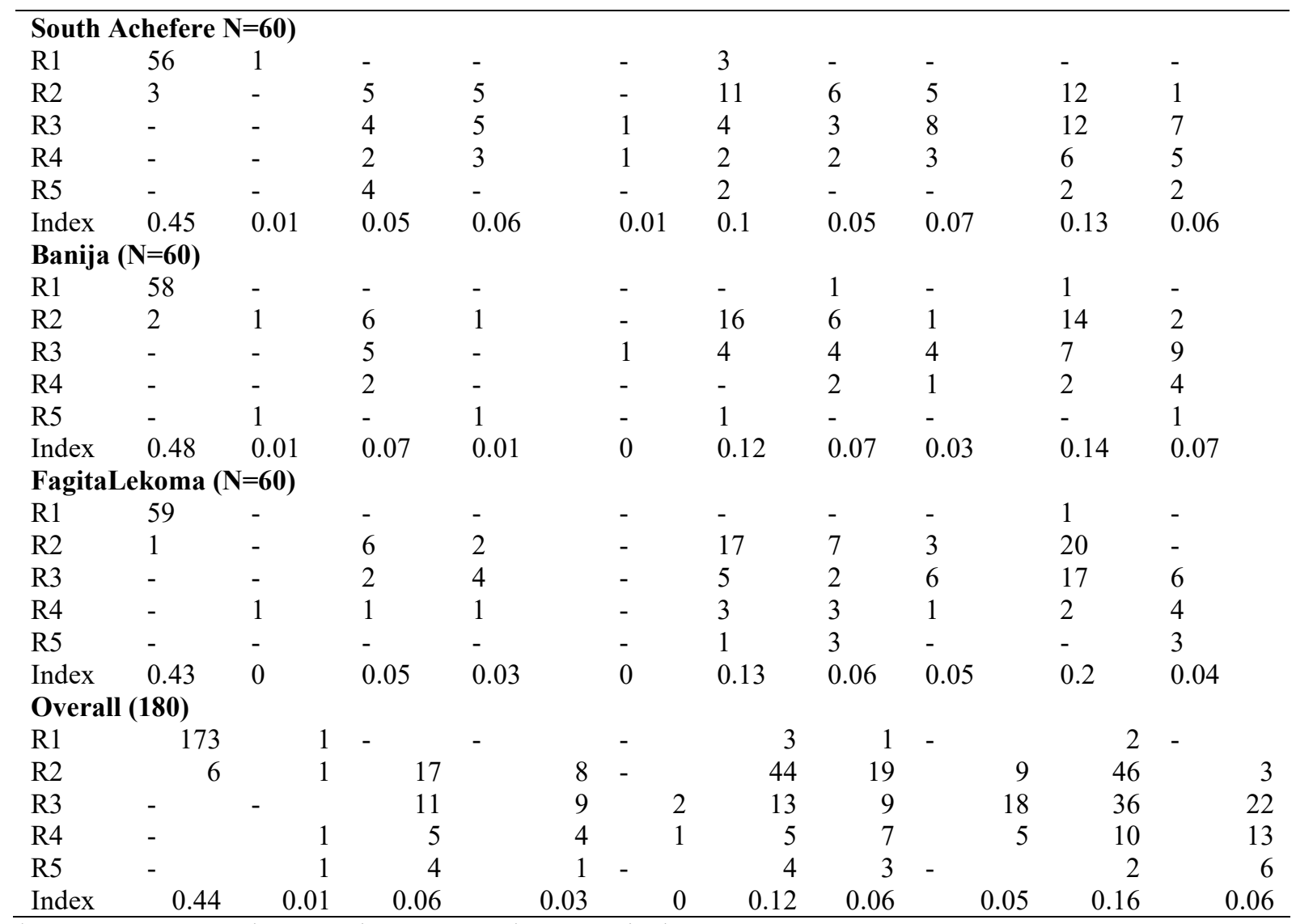

* R1, R2, R3, R4 and R5=Rank 1, 2, 3,4 and 5 respectively.

3.3.4.2. Trait preference for breeding cock of chicken producers

Ranking of trait preferences for breeding cocks by the respondents is shown in 7. Ranking index of the result indicates that cock with good body conformation/good physical appearance was ranked first and followed by large body size and resistance for diseases in all the study area. The result indicates that the chicken producer knew the importance of selecting the breeding cocks and they were primarily concerned with the improvement of body conformation, live weight and disease resistance (adaptation trait)rather than market and cultural values such as plumage color and comp shape and type. Preference of live weight indicates that farmers are interested in chicken that can grow fast and have large body size for both home consumption and sales to get cash income. The current result corresponding to the finding of Getachew et al. (2014) reported traits considered for male were weight $(0.19)$, comb type (0.2) and physical appearance (0.17) in South Wollo Ethiopia. Adisuet al. (2013) also reported that body conformation (0.168), live weight $(0.165$ and adaption (resistance to disease) $(0.115)$ were the most emphasis traits for selection of the breeding cock in north Wello, Amhara region. However, contrary toFeyera (2016) who reported that breeding cock's importance for market and cultural values like as plumage color and active courtship was desirable traits in western Oromia region. Therefore, economical trait such as growth rate and body size of male chicken and egg production of female chicken is essential for the development of breeding objectives for improvement of indigenous chicken in the study area. 
Table 7. Ranking of trait preferences by the respondents for breeding cocks in the study area

\begin{tabular}{|c|c|c|c|c|c|c|c|}
\hline \multirow{2}{*}{$\begin{array}{l}\text { Distri } \\
\text { ct }\end{array}$} & \multicolumn{7}{|c|}{ Qualities of a good breeding cock } \\
\hline & $\begin{array}{l}\text { Large body } \\
\text { size }\end{array}$ & $\begin{array}{l}\text { Better meat } \\
\text { taste }\end{array}$ & $\begin{array}{l}\text { Feed } \\
\text { efficiency }\end{array}$ & $\begin{array}{l}\text { Good } \\
\text { conformation }\end{array}$ & body & $\begin{array}{l}\text { Disease } \\
\text { resistance }\end{array}$ & $\begin{array}{l}\text { Longevi } \\
\text { ty }\end{array}$ \\
\hline \multicolumn{8}{|c|}{ South Achefere $(\mathrm{N}=60)$} \\
\hline $\mathrm{R} 1$ & 8 & - & - & 34 & & 14 & 4 \\
\hline $\mathrm{R} 2$ & 14 & 1 & 3 & 17 & & 6 & 8 \\
\hline R3 & 9 & - & 2 & 5 & & 11 & 16 \\
\hline $\mathrm{R} 4$ & 2 & 3 & - & 1 & & 4 & 2 \\
\hline R5 & 2 & - & - & - & & - & - \\
\hline Index & 0.2 & 0.02 & 0.03 & 0.39 & & 0.21 & 0.16 \\
\hline \multicolumn{8}{|c|}{ Banija $(\mathrm{N}=60)$} \\
\hline $\mathrm{R} 1$ & 16 & - & - & 31 & & 9 & 2 \\
\hline $\mathrm{R} 2$ & 15 & 1 & - & 13 & & 13 & 8 \\
\hline R3 & 14 & 1 & 3 & 1 & & 7 & 5 \\
\hline $\mathrm{R} 4$ & - & - & 1 & - & & 2 & 1 \\
\hline R5 & - & - & - & - & & - & 1 \\
\hline Index & 0.3 & 0.01 & 0.02 & 0.35 & & 0.2 & 0.1 \\
\hline \multicolumn{8}{|c|}{ FagitaLekoma $(\mathrm{N}=60)$} \\
\hline $\mathrm{R} 1$ & 16 & - & - & 25 & & 16 & 4 \\
\hline $\mathrm{R} 2$ & 15 & - & - & 13 & & 11 & 13 \\
\hline R3 & 7 & 1 & 2 & 7 & & 7 & 11 \\
\hline R4 & - & - & - & 1 & & 2 & 2 \\
\hline $\mathrm{R} 5$ & - & - & - & - & & - & 1 \\
\hline Index & 0.26 & 0 & 0.01 & 0.32 & & 0.24 & 0.17 \\
\hline \multicolumn{8}{|c|}{ Overall } \\
\hline R1 & 40 & - & - & 90 & & 39 & 10 \\
\hline $\mathrm{R} 2$ & 44 & 2 & 3 & 43 & & 30 & 29 \\
\hline R3 & 30 & 2 & 7 & 13 & & 25 & 32 \\
\hline R4 & 2 & 3 & 1 & 2 & & 8 & 5 \\
\hline R5 & - & - & - & - & & - & 2 \\
\hline Index & 0.25 & 0.01 & 0.02 & 0.36 & & 0.22 & 0.15 \\
\hline
\end{tabular}

* R1, R2, R3, R4 and R5=Rank 1, 2, 3,4 and 5 respectively.

\subsubsection{Chicken Breed Preference}

The polled analysis of index of breed preference of chicken producers are indicated in Table 8.Exotic breed is the first preferred chicken by producers in the study area. The reason for exotic chicken breed preference could be because of their potential to produce a lot of eggs, larger body size and weight for meat and good feed efficiency. Cross breeds (local x exotic) are the second preferred chicken breed of by chicken producer. The result implicates that chicken producers prefer to handle and rear high producing chicken ecotypes which are dual purpose chickens. 
Table 8. Ranking index of breed preference of chicken producers in the study area

\begin{tabular}{|c|c|c|c|c|}
\hline \multirow[t]{2}{*}{ Breed } & \multicolumn{3}{|c|}{ District } & \multirow[t]{2}{*}{ Overall } \\
\hline & $\mathrm{S} /$ Achefer $(\mathrm{N}=60)$ & Banija $(\mathrm{N}=60)$ & F/Lekoma $(\mathrm{N}=60)$ & \\
\hline \multicolumn{5}{|c|}{ Local chicken } \\
\hline R1 & 9 & 4 & 5 & 18 \\
\hline $\mathrm{R} 2$ & 16 & 18 & 9 & 43 \\
\hline R3 & 31 & 35 & 39 & 105 \\
\hline Index & 0.27 & 0.25 & 0.21 & 0.24 \\
\hline \multicolumn{5}{|c|}{ Improved local } \\
\hline R1 & - & - & - & - \\
\hline $\mathrm{R} 2$ & - & 2 & - & 2 \\
\hline R3 & - & - & - & - \\
\hline Index & - & 0.01 & - & 0.004 \\
\hline \multicolumn{5}{|c|}{ Exotic chicken } \\
\hline R1 & 42 & 46 & 50 & 138 \\
\hline $\mathrm{R} 2$ & 4 & 4 & 3 & 11 \\
\hline R3 & 4 & 2 & 2 & 8 \\
\hline Index & 0.41 & 0.44 & 0.47 & 0.44 \\
\hline \multicolumn{5}{|c|}{ Cross chicken } \\
\hline R1 & 8 & 10 & 5 & 23 \\
\hline R2 & 40 & 34 & 45 & 119 \\
\hline R3 & 6 & 5 & 2 & 13 \\
\hline Index & 0.33 & 0.30 & 0.32 & 0.32 \\
\hline
\end{tabular}

* R1, R2 and R3=Rank 1, Rank 2, and Rank 3 respectively.

\section{SUMARY AND CONCLUSION}

Mating system of chickens in the study area is both uncontrolled and controlled, however, uncontrolled is predominate one due to free scavenging production system. Majority of chicken producers were tries to improve their indigenous chickens with either both line breeding and cross breeding. In the study area, chickens were used as source of income for rural households in terms of egg sale and live adult chicken sale and the result implicates that farmers have multiple breeding purpose of indigenous chicken. Chicken producers gave greatest attention to economic trait, functional trait and adaptation trait for selection of breeding hen and body conformation, live weight and disease resistance for the selection of breeding cock. chicken producer prefers exotic breeds because of their potential to produce a lot of eggs, larger body size and weight for meat and good feed efficiency. Therefore, for the development of breeding program for improving indigenous chicken understanding of breeding practices and objectives and trait preferences of chicken producers are indispensable. Based on the survey result development of breeding programs for improving the productivity of indigenous chicken in the study area should target economic, functional and adaptation traits and consider the current and future production prospective.

\section{REFERENCES}

Addisu G, Hailu M, Zewdu W, 2013. Indigenous Chicken Production System and Breeding Practice in North Wollo, Amhara Region, Ethiopia. Poultry Fisheries Wild Life Science.

CSA (Central Statistic Authority), 2016. Agricultural sample survey 2015/2016, vol. II. Report on livestock and livestock characteristic, bulletin 583 .

CSA (Central Statistical Authority), 2011. Summary andstatisticalreportofthe2007 populationand housing census, federal democratic republic of Ethiopia, population census commission, Addis Ababa.

Feyera B, 2016. Phenotypic Characterization of Indigenous Chicken and Their Production System in GobuSayo,BakoTibe and Danno Districts of Western Oromia, Ethiopia'. Msc thesis, Haramaya university, Haramaya, Ethiopia.

Fissha M, AzageT, and Tadelle D, 2010. Indigenous chicken production and marketing systems in Ethiopia: Characteristics and opportunities for market-oriented development. IPMS Improving Productivity and Market Success of Ethiopian Farmers Project Working Paper 24. Nairobi, Kenya, ILRI.

Getachew B, Kefelegn K and Negassi A, 2016. Study of Indigenous Chicken Production System in Bench Maji Zone, South Western Ethiopia. Global Journal of Science Frontier Research: D Agriculture and Veterinar. Volume 16.

Hailemichael N, 2013. On-farm phenotypic characterization of indigenous chicken and chicken production systems in Southern Zone of Tigray, Northern Ethiopia, Msc thesis, Haramaya university, Haramaya, Ethiopia. 
Halima H, 2007. Phenotypic and genetic characterization of indigenous chicken populations in North-West Ethiopia. Ph.D Thesis. Submitted to the faculty of natural and agricultural sciences department of animal, wildlife and grassland Sciences. University of the Free State, Bloemfontein, South Africa.

Kosgey, I.S, 2004. Breeding Objectives and Breeding Strategies for Small Ruminant in the Tropics. Ph.D. Thesis, Wageningen University, Wageningen.

Netsanet T, 2017. On-farm phenotypic characterization of indigenous chicken and their husbandry and breeding practices, in debark and dabat districts, north gondar, ethiopia. Msc thesis, haramaya university, Ethiopia.

Nigussie D, Tadelle D, Vander Waaij LH, Van Arendonk JAM, 2010. Morphological features of indigenous chicken populations of Ethiopia. Animal Genetic Resources, 46:11-23.

Okeno TO, Bett RC, Kahi AK, Peters KJ, 2011. Economic values for resistance to helminthosis and newcastle disease in indigenous chicken in the tropics. Journal of Veterinary Advance 1: 1-10.

Sefa S, Gebrela T, Demissie H, 2016. Village Chicken Production System and Constraints in Lemo District, Hadiya Zone, Ethiopia. Poultry, Fish and Wild life Science 4:158. doi:10.4172/2375-446X.1000158

Tadelle D, Million T, Alemu Y and K J Peters, 2003. Village chicken production systems in Ethiopia: flock characteristics and performance. Journal of Livestock Research for Rural Development. 